\title{
SOCIAL STRUCTURE, ITS EPISTEMOLOGICAL USES, AND THE CONSTRUCTION OF THE SUBJECT IN BOURDIEU'S SOCIOLOGY
}

\author{
Estructura social, sus usos epistemológicos \\ y la construcción del sujeto en la sociología de Bourdieu
}

Daniel Leyton*

\begin{abstract}
This paper discusses the notion of social structure in Pierre Bourdieu's sociology. It contextualizes the notion of social structure and its conception in Bourdieu's work highlighting the central functions the concept has had in the field of sociology. Taking into account some relevant critical positions around the concept of social structure and Bourdieu's sociology a critical exam of those positions is developed, deploying an alternative interpretation of the use of the concept given by the French sociologist, showing its contribution to the construction of an autonomous subject with capacity of collective agency. The concept of social structure operates as a generative tool of epistemological vigilance against reductionist representations of the subjects and their conditions of existence allowing the emergence of notions such as temporal dislocation, indeterminacy, dialectic, and socio-analysis which are contributing to the construction of a more emancipated subject.
\end{abstract}

Keywords: Social structure, habitus, temporal dislocation, socio-analysis, epistemology.

\footnotetext{
"Centro de Investigación y Desarrollo de la Educación (CIDE), Facultad de Educación, Universidad Alberto Hurtado. Santiago, Chile/Centre for Higher Education and Equity Research (CHEER), University of Sussex. Brighton, United Kingdom. Correo electrónico: dleyton@uahurtado.cl
}

Received February, 16, 2014. Accepted September, 4, 2014. 


\section{RESUMEN}

El artículo discute la noción de estructura social en la sociología de Pierre Bourdieu. Se contextualiza la noción de estructura social y su concepción en la obra de Bourdieu enfatizando las funciones centrales que el concepto ha tenido en el campo sociológico. Tomando en cuenta algunas posturas críticas relevantes en torno al concepto de estructura social y la sociología de Pierre Bourdieu se desarrolla un examen crítico de ellas desplegando una interpretación alternativa del uso que el sociólogo francés le da al concepto destacando la contribución de dicha noción a la construcción de un sujeto autónomo con capacidad de agencia colectiva. El concepto de estructura social opera como una herramienta generativa de vigilancia epistemológica en contra de representaciones reduccionistas del sujeto y sus condiciones de existencia permitiendo la emergencia de nociones como dislocamiento temporal, indeterminación, dialéctica y socio-análisis las cuales contribuyen a la construcción de un sujeto social más emancipado.

Palabras clave: Estructura social, habitus, dislocamiento temporal, socio-análisis, epistemología.

\section{INTRODUCTION}

The concept of social structure is one of the core notions in social science. It refers to social forces and pathways which are external, relatively autonomous from and more than the sum of the individuals. On the other hand its uses in social theory trigger other fundamental questions on history, explanations, and agency (Porpora, 2002). Despite its centrality and frequent use, since the 1970 s there is a wide recognition of its problematic status as a vague notion lacking of a share definition, function, and understanding (Homans, 1975; Porpora, 2002; Lopez and Scott, 2008; Jenkings, 2010).

This article is an attempt to contribute to think about the function of the notion of social structure, not pretending to give a systematic definition or to deploy a dissectional analysis of its components, but rather exploring its link to an epistemological and clinical critique of the constructions of individuals, underlining the dynamic -not staticdimension it contains and its potential contribution to the construction of a more realistic emancipated subject. In order to address this problem, I draw primarily in Bourdieu's work by discussing the function he gave to social structure emphasising its link to his critical epistemological stance and his criticism to different representations of subjects.

\section{CONTEXTUALIZING BOURDIEU AND HIS APPROACH TO SOCIAL STRUCTURE AND SUBJECTS}

One of the contributions of the notion of social structure has been to give an understanding of the Hobbesian question about the constitution and reproduction of social order; a question that Bourdieu and colleagues worked intensively in their investigations on educational and social class inequalities (Bourdieu, 1979; 1984; 1990), stressing some mechanisms by which some social structures contribute to inequalities and class domination by transforming socio-historical privilege into social gift or part of the meritocratic practices. From this perspective, we can find numerous and important works that construct evidences showing the power of education to constrain and produce 
enduring patterns of distribution of subjects according to practices, representations, emotions, capitals, and opportunities.

Alongside that prior conception and utility of the notion of social structure there is a more subtle historical function of it. That is, to uncover the shortcomings of an individualistic and utilitarian construction of individuals (King, 2004). This function is linked to the prior one. If the structure has the power to constrain and patter the life of individuals, it also has the power to enable and exclude particular subjects' positioning. From this stance, the categories of comprehension and representations are not completely under the control of the individuals. They are, as Bourdieu following Durkheim insisted, shaped by social structure; embodying expressions of it, "inscribing inside the organism the patterned inertia and constraints of external reality" (Bourdieu and Wacquant, 1992: 13).

For Bourdieu, this notion of social structure goes beyond the description of people's rationalities and social experiences, and therefore, enables us to deepen in those dimensions of existence which are out of individuals control, reason, and everyday awareness. Through this notion one may deploy an analysis with the potentiality to address the power of social structures of constituting individuals' subjectivities and materiality regardless of their will. Bourdieu here is closer to one of his critics. Social structure here is similar to Rancière's (1999) notion of police which has the power to distribute the bodies and subjectivities in the social space, thereby maintaining the power relations, by imposing the boundaries and limits that define what is possible to think, to say, where is possible to place oneself, and what is possible to displace or avoid. For, Bourdieu, similar to Rancière, social structures may constitute a 'common sense' a 'doxa', as the generative matrix of practices and meanings that tends to inhibit some actions and thoughts, presenting them as out of place, impossible to achieve, or not made to the measure of the individuals (Bourdieu, 1993).

Indeed, through the concept of social structure and its relation to the notion of agency, it is possible to deploy a sociological craft by which we can acquire putting into practice an epistemological surveillance about the limits of the representation of the human being as a rational actor capable to develop a course of action based on the awareness of the aims to obtain; the capacity of asses and select the proper means to get the aims, and finally, to decide one course of action based on the deliberation made before. This utilitarian and individualistic stance of human beings overlooks different dimensions like emotions, everyday practices, and cultural and institutional constraining. Particularly, one of the sociological uses of the concept of social structure that Bourdieu deployed is rooted in his epistemological rupture with the rationalistic and scholastic representation of the human being. This aspect of his theoretical production will be presented afterwards.

\section{THE CRITICAL VIEWS TO THE NOTION OF SOCIAL STRUCTURE}

One may distinguish, at least, two main critiques triggered by the notion of social structure that apply direct or indirectly to Bourdieu's sociology. The first is the tendency to reify human beings reducing them simply to effects or reflects of the social structure (Alexander, 1995, 2003; King, 2004; Jenkings, 2006, 2010). The second one, is that most of the theoretical approaches which use the concept stress social reality as a dichotomy constitution, avoiding the existence of social phenomenon that underlines dimensions of society that are neither structure nor agency (King, 2004; Halewood, 2011). 
Regarding to the first one, Richard Jenkings (2010) argues that social structure is a notion that brings into the social science presuppositions which do not represent the empirical or observable social reality properly, impeding the understanding of the human world. These assumptions are referring to the construction of the human being as a reified entity without agency or will. Following this line of argument Jenkings lashes out against Bourdieu by postulating that the French sociologist said one thing but he does the opposite. For Jenkings (2006) an example of this is Bourdieu's claim of overcoming the objectivist-subjectivist dualism and determinism but presenting an endured form of objectivism and a deterministic picture of social process.

Jenkings' vision of these supposed contradictions between dynamic and dialectic social process of the configuration of social structures and their persistent reproduction of enduring patterns led him to reject the concept of social structure evaluating it as a notion that fosters the construction of individuals without the power to act on their own right. He states that the notion of "social structure offers an image of powerful invisible influences [...] operating above our heads or behind our backs. It is a perspective of the human world that discourages a model of human being as capable of agency" (Jenkings, 2010: 142).

In agreement with the above mentioned the humanistic views manifest the necessity to overcome the kind of dualism that gives more power to the structure than to human action. For example, both phenomenology and symbolic interactionism reject the use of the social structure because it fosters a treatment of human beings as a mere reflection of it neglecting the meanings of people's social experiences (Layder, 1994). In this sense, social life is constructed by individuals themselves in their interactions with others. It is not produced by some impersonal entity such as an objective structure which exists outside their experiences. These approaches put at the centre the human being's capacity to construct the world in a meaningful way. That is to say by making sense. They put the meaning and subjectivity outside the social structure (Layder, 1994).

Jeffrey Alexander (1995; 2003) developed a representation of Bourdieu's sociology as materialistic reductionism without giving space for the autonomy and innovation of the individuals. In his interpretation the subjective dimension of culture -through the constitution of the habitus- is just a mirror of the material reproduction of inequalities and social class structure. In this line, Alexander wrote:

The thickets of terminological ambiguity that always mark out a weak program, commentators agree that in Bourdieu's framework culture has a role in ensuring the reproduction of inequality rather than permitting innovation [...] As a result, culture, working through habitus, operates more as a dependent than an independent variable (Alexander, 2003: 18).

In this sense, theoretical tools like habitus and field are misrecognized by Alexander as mediations between social class structure and subjective structure. These concepts, in the view of Alexander, are not defined as social mediations capable of opening a temporal space of indeterminacy and contingency between agents and broader social class structure. Nevertheless, Bourdieu did remind us a fundamental principle of analysis based on the 
temporal dislocation between the tendencies of the habitus inscribed in the structural conditions in which they were produced, and the actual conditions (Gartman, 2007). In fact, according to Bourdieu the analysis of practices is not reduced to the present or past conditions. "They can [...] only be accounted [...] through the scientific work of performing the interrelationship of these two states of the social world that the habitus performs" (Bourdieu, 1993: 56).

It is this principle one of the conditions that establish the relative autonomy of the human practices in front of the external constrains and that does not allow the direct determination of the structure over the individuals.

In relation to the second critique to the concept of social structure, we can see that this notion is related to the concept of agency, stressing an image of society as shaped by individual agents and structure that are both the boundaries and limits of their action, and the social conditions of possibilities of that social practices and actions. According to King (2004) these oppositions have the ontological effect of constructing a representation of society which forgets the social interactions as constituent part of social life. In this sense, King pointed out that there is a link between the dualistic ontology of structure and agency and the representation of the society as the product of isolated individuals confronted to powerful structures that dominate them. In this representation sociology, he said, has forgotten the hermeneutic dimension of the social based on shared understanding constructed during the social interactions (King, 2004).

Similar to King but with a more nuance provocation, Halewood (2011) interpreting Whitehead's philosophy encourages an interrogation of the theoretical tools that produce this dualistic vision of the world. He pointed out that social theories addressing the structure/agency distinction are inclined to use that opposition to understand all range of social situations without distinguishing when and where this theoretical construction may help to grasp particular social facts. According to him it might be more fruitful to establish the social conditions of existence in which the structure/agency interrelation may give us a good description of the social phenomenon, and to construct different theoretical principles and tools to grasp those social situations that are not following a structure/ agency pattern (Halewood, 2011).

The exposition of these points depicted above allows us to see that all of them share the assumption that the notion of social structure in which they base their questioning is featured just by its static "already made" dimension, ignoring that the notion of structure, based on its semantic root "struere", refers also to the action of building as a process (Lopez and Scott, 2008). Looking backward to the concept and making visible its dynamic nature is important because the sociologists that have tried to disembarrass the static side of the notion by making an effort to get rid of it from the sociological landscape, have ignored the sense of process which is a constitutive part of the notion.

Even though Bourdieu developed insights against the structuralist approaches on social structure as having the power to reduce the individuals as epiphenomenon of them (Bourdieu 1977; 1993), he did not chose to abdicate to the theoretical and empirical work on social structure. Thereby, he deployed an attempt to surpass the static and totalitarian notions of social structure by trying to recover a more dynamic aspect of the concept; that is to say, its process dimensions. Nonetheless, it would be too simplistic to locate 
his efforts entirely in such a traditional dichotomy between static and social dynamic. In his theoretical work he tried to emphasize at the same time the dialectic constitution of structures and the perverse-deterministic logic of the relational constitutions of them without giving them the presuppose forces to reify the subjects.

The dialectic and potential perverse-deterministic constitution of social structure was exposed in a systematic way in his classic work together with Passeron Reproduction in Education, Society and Culture (1990). Despite the common sense criticism about his top-down and deterministic view of social structure in this oeuvre, one may see that in his description of the emergence of the educational system he deployed a DurkheimianWeberian synthesis: the education system as social structure was produced by the constitution of a body of specialists governed by particular interests in monopolize certain space of practice and knowledge -the Weberian dimension-, and as correlative to the historical formation of distinction rules and sanctions oriented to legitimate its function of reproduction by the legal inculcation of the diploma and the educational organization of teachers -the Durkheimian dimension-. In this sense, it is not a bottom-up or top-down social formation; rather it is between and beyond these historical processes by which social structure appears as the possibility to produce and maintain, for its own reproduction, a homogeneous and enduring habitus, and furthermore, showing that the process of social differentiation of the social spaces is not possible without the agency and differentiated practices and social interactions of individuals.

Even here, he was not proposing that individuals in the same social position, defined by their relation with others in different positions in the social space, have the same way of perceiving, assessing and acting. When Bourdieu observed that people in relatively similar social position are likely to experience similar situations he did not assume the possibility to determine the practices of one class facing a similar situation. As Fuchs (2003) sharply asserts:

It only suggests that to a certain extent members of the same class will show, as Bourdieu says, 'homologous' behaviour in a number of situations [...] what Bourdieu suggests is that a certain extent of uncertainty remains in all social situations, even in cases in which the agents' habitus seem to be perfectly harmonized (2003: 393).

In this course, Fuchs stated that habitus, as a mediated structure between individuals and social structures, implies a dialectic relation between freedom and determinism in a given space to variable degrees of uncertainty and creativity. It is the habitus that allows the development of creative practices and framed invention at the same time (Fuchs, 2003). In fact, one of the affinities that Bourdieu encountered with pragmatism and phenomenology, for example, is the emphasis of the concept of habitus in its creative and active relation in the construction of the social world (Bourdieu and Wacquant, 1992). In The Logic of Practice (1993) Bourdieu stated:

[habitus] makes possible the production of all the thoughts, perception and actions inherent in a particular conditions of its productions...the conditioned and conditional freedom it provides is a remote from creation unpredictably novelty as it is from simple mechanical reproduction of the original conditioning (1993: 55). 
By emphasizing the possibility of temporal dislocation and indeterminacy between individuals and broader social structures through the working of habitus and field as mediating concepts, and by stressing the dynamic nature of social structures one can understand the dialectic formation of social structures as an imperfect and problematic process of interaction between the internalization of exteriorities -patterns of practices, interactions, meanings and situations- producing a socialized subjectivity, and the externalization of interiorities through the production of practices an meanings. Therefore, this dialectic process, far from being an expression of a mechanical adjustment of individuals to structures, also indicates a process of dislocation; refusal or indeterminacy opens to subjects. Moreover, the adjustment between agents and social structures is not a principle or social law, but a condition which must be interrogated in order to know how and when it might occur.

\section{BOURDIEU'S EPISTEMOLOGICAL USE OF THE NOTION OF SOCIAL STRUCTURE AND THE CONSTRUCTION OF A REALISTIC AUTONOMOUS SUBJECT}

Bourdieu's attempt to address the problem of the relationship between human agency and social structure is well known as an endeavour to overcome the dualism between objectivism and subjectivism. The French sociologist pointed out that among all dichotomies employed in the social science to give an account of the social life, the most dominant and corrosive is the opposition between subjectivism and objectivism. These are one of the imperative forms of knowledge by which social science has been trying to grasp and represent the social world. According to Bourdieu, these approaches are unable to give a more accurate account and explanation of the logic of the social because they are just focused on the subjectivity-rationality and experience of the subjects (phenomenology, existentialism, rational choice theory) or on the social determinants and laws that govern the subjects from outside (structuralism) (Bourdieu, 1993). Notwithstanding, while he recognized their limits, he did not unrecognize their importance in the process of constructing the knowledge of the social.

The very fact that this division constantly reappears in virtually the same form would suffice to indicate that the modes of knowledge which it distinguishes are equally indispensable to a science of the social world that cannot be reduced either to a social phenomenology or a social physics (Bourdieu, 1993: 25).

These epistemological ruptures, I argue, were made through the use of the concept of social structure as a generative tool of epistemological vigilance against different representations of the subjects and their conditions of existence developed by the objectivism and subjectivism.

Bourdieu's critical account of the objective social structure starts recognizing that this notion is based on the disciplinary construction of laws, regularities and objective relationships between agents (patterns), that govern the social world independently of the subjects consciousness and wills. Taking into account this logic of inquiry, Bourdieu posed 
that regularities that conform social structures may be observed from outside, measured and mapped without taking into account the individuals' social representations of them. Although, objectivism does not seek to describe and explain the pre-scientific experience of the world, in order to grasp the social space, it does draw attention on the conditions by which doxic experience of the world is possible (Bourdieu, 1993).

From this point of view is possible to pose that Bourdieu's notion of social structure as objective structure is founded on the 'no-consciousness principle', thus, serves as instrument to struggle against the disembedded representation of agency. In other words, it serves as an instrument of criticism to the image of human beings as constituted with free will and fully aware of their actions and purposes, and giving a space for an analysis of the power of affects and raw emotional states in the constitution of the social. As Bourdieu emphasized:

If sociology as an objective science is possible, this is because there are external, necessary relationships, independent of individual wills, and as it were unconscious (in the sense that they are not available to simple reflection) which can only be grasped by means of a detour through objective observation and experimentation (Bourdieu et al. 1991: 19).

The external, objective space of relational positions is therefore an existence that must be constructed by the epistemological tools which may orient and warn the sociological observations. In this sense, Bourdieu pointed out that the subjects-objects of knowledge have no external and independent existence; they must be constructed and not passively registered (Bourdieu, 1993).

And, in Outline of a Theory of Practice he stated:

Hence it is not sufficient [...] to break with native experience and the native representation of that experience: It has to make a second break and question the presuppositions inherent in the position of and outside observer, who, in his preoccupation with interpreting practices, is inclined to introduce into the object the principles of his relation to the object (Bourdieu, 1977: 1-2).

This quotation refers to the consequences of not putting into practice the same instruments of knowledge to grasp the social world towards the scientific field and scientists positions in the social world. In this sense, Bourdieu claims that by not applying the instrument of knowledge toward the comprehension of the scientific practices and conditions we develop a disposition to depict and explain the social without knowing the effect of the relationships between the knowing subject and the knower subject (Bourdieu 1977; 1993); therefore, without knowing the performativity of social theory.

Bourdieu acknowledged the necessity to move away from structuralist notion of structure in order to avoid the risk of constructing a model of reality based on autonomous structures gifted by the ability to act as agents without human agency, and produce passive individuals which exist only as supporters and reflections of external structures. In the Logic of Practice (1993) Bourdieu stated that the categories used by structuralism are treated as categories endowed with the power to determine the subjectivities and practices of the agents without the agency or complicity of the agents. In this sense, he was referring to 
the ignorance made by objectivism of the possibility of agents to develop strategies, and individual and collective struggles in order to preserve or transform the value and meaning of the capitals or their distributions that reproduce arbitrary hierarchies.

Also, he pointed out that in such use of the theoretical model, the objectivism endowed theoretical categories such as structures, culture or social classes with the power to inscribe on social groups particular subjectivities and responsibilities to take specific actions without taking a proper account of their conditions of struggles.

Objectivist discourse tends to constitute the model constructed to account for practices as a power really capable of determining them. Reifying abstractions (in sentences like 'culture determines the age of weaning'), it treats its constructions -'culture', 'structures', social 'classes' or 'modes of production'- as realities endowed with a social efficacy. Alternatively, giving concepts the power to act in history as the words that designate them act in the sentences of historical narrative, it personifies collectives and makes them subjects responsible for historical actions (Bourdieu, 1993: 37).

In this sense, the "reality of the model" is used not just to construct social reality but to impose social reality, subjectivities, and historical roles according to that objective and subjective state but, paradoxically, not recognizing the principle of production of the social practices and agency so without endowing them with power to act upon their own social reality.

Against the subjective perspective; the familiar and naturally lived experience of the social world, the notion of social structure allows us to operate an epistemological rupture against common sense of the world objectifying the social reality by constructing abstract categories in order to build tools of epistemological surveillance against the illusion of spontaneous knowledge (Bourdieu et al, 1991; Bourdieu, 1977; 1993). In other words, it can be said that this epistemological operation enables social scientist to undermine the illusions in the transparency of social world, suggesting that behind the surface of the world sociology has to uncover the deepest structures that preserve the social order, as well as the mechanism or principles that tend to sustain its reproduction or transformation (Bourdieu and Wacquant, 1992).

In regard to Bourdieu's critical account of subjectivist construction of human being he used the notion of social structure to struggle against the illusions raised by subjectivism, a perspective which builds an image of human beings as free, rational and conscious, and as owners of the entire meaning of their actions. For Bourdieu these are the conceptions of human beings which are behind the defence of the human subjectivity and rationality.

In response to this posture, that emphasizes the criticism to the concept of social structure as the powerful entity which decentralizes the subject by stealing its agency capacity, Bourdieu criticized those who viewed social practices strategically oriented to a conscious and free project, not recognizing the existence of enduring dispositions (1993). For example, he questioned the rational actor theory because it tends to explain the actions of the agents as strategies mediated by rational calculation, where the agents assume an utilitarian perspective deploying practices based on conscious reasons and planned purposes (Bourdieu, 1998), and as if human intentions were the causes of their actions (See Elster, 1989). Furthermore, he questioned the tendency of rational choice theory to explain the 
regular elections as rational decisions according to their preferences and interests without linking those interests to differentiated and autonomous social spaces as one of the factors of those dispositions. In this respect, Bourdieu said that the rational choice theory's notion of interest imposes the logic of a particular field (the economic field) to all the other different spaces (Bourdieu, 1998). He pointed out that this false assumption is due to the fact that there is not a question about the economic and social conditions of the formation of dispositions that cause the agent to make reasonable choices, tailored to the objective possibilities, rather than rational ones (Bourdieu, 1993).

It can be inferred that, although the humanistic and rationalistic perspectives are against the reification of the subject, for Bourdieu their construction of human beings leads to unacknowledged the existence of meaning beyond the subjectivity and intersubjectivity, which is crystallized in institutions. That type of institutionalized meaning is not chosen in a deliberate manner for individuals ${ }^{1}$.

\section{BORDIEU'S SYNTHESIS AND THE REALISTIC CONSTRUCTION OF THE AUTONOMOUS SUBJECT}

Regarding Bourdieu's criticism of objectivist and subjectivist notion of social structures, he posed the dialectic between these two visions, without forgetting its limits. By taking into account the restrictions of objectivism's notion of structure Bourdieu recognized the necessity to move from the statistical measure of the structure to the theory of the mode of production of practices (Bourdieu, 1977). On the other hand, against the unrecognized bond between social structures and social experiences stressed by humanistic views, Bourdieu claimed the existence of correspondence between social structures and subjective dispositions and distinctions of the social world (Bourdieu and Wacquant, 1992):

The site of the dialectic of the opus operatum [the outcomes]) and the modus operandi [the modes]; of the objectified products and the incorporated products of historical practice; of structures and habitus (Bourdieu, 1993: 52).

Here, Bourdieu was talking about the habitus as the mediated mechanism constituted in the dialectic process between the internalization of the external forces and prior conditions of existence and the externalization of the internality through the production and construction of the social structure by the work of agents during their social relations and struggles. As Fuchs pointed out, when Bourdieu was discussing the dialectic process between the opus operatum and modus operandi he was saying that the habitus may constrain practices but also can be the product of creative social relations between human beings (Fuchs, 2003).

\footnotetext{
${ }^{1}$ It is worth mentioning that Elster, in his book Explaining social behaviour. More nuts and bolts for the Social Sciences (2007), develops a progressive disaffection to the rational choice theory recognizing that: Rational-choice theory [...] is helpful in highly structured situations about which a great deal is known, such as testing for cancer, but less so in unknown environments [...] Any choice-based explanation of behaviour is subjective. Not all subjective explanations assume, however, the transparency of the agents to themselves and the relentless search for optimality that are the hallmarks of rational -choice explanations (2007: 208-212).
} 
It is in this intersection between social structure as a general patterned social space, field as differentiated and relative autonomous space of struggles, and habitus as embodied structure, which enables the relation between individuals and societies, through which we can identify in Bourdieu's work another particular use of the notion of social structure which reveals the internal connection between his analytical scientific work and his practical interest to contribute to a more autonomous subject by revealing the enduring patterns of inequalities embedded in arbitrary historical relations of symbolic domination. These relations tend to appear as necessary and natural to the experiences of the subjects, thus may be legitimated by them. This link may be clearer if we employ a definition of habitus that emphasizes the dimension of its naturalization and unrecognizing, unnoted but pervasive and profound incarnation. One can find this definition in the following quotation ${ }^{2}$ :

The practical world that is constituted in the relationship with the habitus [...] is a world of already realized ends procedures to follow, paths to take [...] This is because the regularities inherent in an arbitrary condition [...] tend to appear as necessary, even natural, since they are the basis of the schemes of perception and appreciation [...] The 'unconscious' $[\ldots]$ is never anything other than the forgetting of history which history itself produces by realizing the objective structures that it generates in the quasi-natures of habitus (Bourdieu, 1993: 53-56).

In other words, the habitus as embodied structure is the embodied history, incorporated into the body and mind of the subjects, naturalized and forgotten as social history by the unconscious internalization. In this sense, Bourdieu reminds us that one of the perverse effects of the articulation between the practical sense and objectified meaning into the social structures is the production of the common sense that may have the effect of avoiding all the practices perceived incompatible with the consensus between regular practices and regular logics that these practices produce and by which are produced.

This process of incarnation produces logics of arbitrariness and domination due to the practices and schemas of perception and classification that agents deploy, producing a representation of social order based on the unequal distribution of capitals and symbolic power as necessary and natural.

One can pose that he was trying to build up a more complex and totalizing concept of human subject as producer and reproducer of society but also as product of it. This attempt is expressed in the notion of social structure as embodied structure. In this sense, the notion of social structure in Bourdieu can address the problem of reification neither reducing the subject to pure subjectivity; freedom or individual rationality, nor constructing the subject as totally determined by social structures. Instead, he was attempting to explore the conditions of possibility of freedom by recognizing, first, the

\footnotetext{
${ }^{2}$ Bourdieu's classical definition of "habitus" refers to the "systems of durable, transposable dispositions, structured structures predisposed to function as structuring structures, that is, as principles of the generation and structuring of practices and representations which can be objectively 'regulated' and 'regular' without in any way being the product of obedience to rules, objectively adapted to their goals without presupposed a conscious aiming at ends or an express mastery of the operations necessary to attain them and, being all this, collectively orchestrated without being the product of orchestrating action of a conductor" (Bourdieu, 1977: 72).
} 
multiple dimensions of human existing as social being, which means acknowledging that we are instantiated as particular bodies-subjects by our social and cultural backgrounds (history, institutions, social relations and biographies) which are internalized in our body as matter of knowledge, dispositions and practices.

On the other hand, defining habitus as a particular type of social structure-embodied and mediating structure-, he was able to introduce time and thereby the indeterminacy and relative autonomy of the agents from the social structures. Nevertheless, the meaning and potential of this relative freedom needs to be triggered by specific social mechanisms and political involvement due to the tendency of habitus to substantiate its arbitrary and historical constitution.

One of the ways of fostering practices of freedom is by bringing to light the conditions and logics of the social laws that shape the power operations of social structures which configure the hierarchical stratification of positions, subjectivities and values, showing their arbitrariness with the aim to open the possibility to question the dominant modes of doing and perceiving things crystallized in the common sense. Following one line of interpretation of Bourdieu's sociology, one can say that this needs to be made through the socio-analysis. This notion, according to Bourdieu refers, firstly, to the reflexive process by which social scientists may gain autonomy by applying critical sociological tools to their own social determinations; history; position and practices that may explicit the un-thought categories of knowledge (Bourdieu, 1992), thereby without imposing an ethnocentric or scholastic point of view far away from the world of practice (Bourdieu, 1998). On the other hand, this scientific socio-analysis allows social scientists to be powerfully affected by the experience and languages of the people outside the social science field, exercising the art of understanding through the exercise of listening but submitting this effects to a critical sociological thinking (e.g. Bourdieu, 1999).

The second meaning that we can find in the notion of socio-analysis is contained in his text Sketch for a Self-Analysis (2007). From here, a socio-analysis can be understood as the process by which social agents gain autonomy by reconstructing their biographies and collective history through a reflexive exercise that brings to light social determinations and possibilities that shape their lives allowing them to re-signify their subjectivities by questioning and limiting the mechanism of social domination (See Frangie, 2009). For Bourdieu, this socio-analysis must be articulated to the social scientists' work. They may engage not just historizing the operations of social structure but making their knowledge public and sharing it with dominated and subaltern groups helping them to speak and encouraging them to display informed collective actions against the common sense and unequal social order (Bourdieu, 2001). We can see an example of this position in the preface of the English edition of Masculine Domination, where Bourdieu wrote:

[The] knowledge of the objective structures and cognitive structures of a particularly wellpreserved androcentric society ...provides instruments enabling one to understand some of the best concealed aspects of what those relations are [...] then one has to ask what are the historical mechanisms responsible for the relative dehistoricization and eternalization of the structure of the sexual division and the corresponding principles of division. Posing the question in those terms marks an advance in the order of knowledge which can be the basis of a decisive advance in the order of action [...] This strictly political mobilization, which would open for women the possibility of a collective action of resistance $[. .$.$] To call on$ 
women to engage in a political action to invent and impose forms of collective organization and action and effective weapons, especially symbolic ones, capable of shaking the political and legal institutions which play a part in perpetuating their subordination (2001: vii-ix).

For Bourdieu, the reflexive exercise through the socio-analysis is both an epistemological work and a source to promote and engage within informed political actions but it was not, for him, an individual enterprise; rather the reflexive socio-analysis must be a collective endeavour. He was calling for a collective organization in the field of social science and in the wider social space because of his awareness of the operations of the social structures as mechanism of dehistoricization and substantiation of the social processes and, however at the same time, he was also aware about the potential existence of the space of autonomy thanks to the temporal dislocation between the habitus and the social structures produced by the actions of agents. It is in this theoretical context that we may understand the intimate link between his epistemological uses of the notion of social structure, his construction of subjects, and his commitment with the socio-analysis as a way of engaging with broader problem regarding social inequality and suffering.

\section{CONCLUSION}

Bourdieu's notion of social structure, as a basic concept that supports and triggers his political sociology and engagement expresses his attempt to establish the "real" possibilities of imagining different routes or pathways. In doing so, he pointed out the necessity to struggle against the reification of the subject which operates by the image of human beings with an intimate subjectivity impervious to the social. In that case, building a socialized subject becomes an epistemological tool to struggle against the reification by de-socializing them, and reinforcing the importance to construct a more realistic social subject.

In this sense, Bourdieu, in the same line as Tom Bottomore (1975), was aware about the importance of reconciling the conception of social structure that emphasizes the enduring nature of social life with the historical capacity of individuals to maintain, reproduce, reinterpret and interrupt the social order. To see the social structure as a permanent dialectic process, as Bourdieu did, enables us to move away

from the idea of an abstract impersonal social structure which is fixed and given once for all, and makes a place for that aspect of social...namely, the production and reproduction of society by real human beings living and thinking in a particular milleu (Bottomore, 1975: 160).

His political engagement was not a contradiction between his sociological work and his public interventions. Rather it was the logical and ethical consequence of his reflexive and political sociology. The socio-analysis and in general the contribution that sociology may do to the questioning of social foundations of the unequal order of modern societies may be interpreted as one of the mechanisms by which the theoretical model of practice, that pretends to get closer to the reality of the model in opposition to the theoretical reason based on the model of reality, may overcome the distance between its 
indeterminacy and contingent dimension and the concrete logic of social practices. In other words, it is a strategy to put in practice the theoretical model of practice proposed by Bourdieu moving from the theoretical model of practice to the practice of the model.

Thus, is by translating and sharing the reflexive instruments of sociological analysis to the social subjects that, as social scientists, we may contribute to make recognizable the conditions of possibility of a socially contextualized autonomy and to disembarrass or question the imposition of practices and subjectivities. By collaborating in the process of socio-analysis by trying to convey the nuanced understanding of social structures, the relative autonomy of social subjects may move from the theoretical or potential possibility to a more probably practical reality.

\section{REFERENCES}

Alexander, Jeffrey. The meanings of social life: A cultural sociology. New York: Oxford University Press, 2003.

Fin de siècle social theory: Relativism, reduction, and the problem of reason. London: Verso, 1995.

Bottomore, Tom. "Structure and History". In Peter Blau (Ed.), Approaches to the study of Social Structure. New York: The Free Press, (1975): 159-171.

Bourdieu, Pierre. Sketch for a Self-Analysis. Chicago, London: The University of Chicago Press, 2007.

. Outline of a Theory of Practice, Cambridge: Cambridge University Press, 1977.

. Distinction. A social critique of the judgement of taste. Cambridge, Massachusetts: Harvard University Press, 1984.

. The Logic of Practice. Cambridge: Polity Press, 1993.

Practical Reason. On the Theory of Action. Stanford, California: Stanford University Press, 1998.

-."Understanding". In Pierre Bourdieu (Ed.), The Weight of the World. Social Suffering in Contemporary Society. Stanford, California: Stanford University Press, (1999): 607-626.

Masculine Domination. Stanford, California: Stanford University Press, 2001.

Sketch for a Self-Analysis. Chicago, London: The University of Chicago Press, 2007.

Bourdieu, Pierre \& Passeron, Jean-Claude. The inheritors. French students and their relation to culture. Chicago and London: University Chicago Press, 1979. 
Bourdieu, Pierre; Chamboderon, Jean-Claude \& Passeron, Jean-Claude. The Craft of Sociology. Epistemological preliminaries. Berlin, New York: Aldine de Gruyter, 1991.

Bourdieu, Pierre \& Wacquant, Loïc. An invitation to reflexive sociology. Cambridge : Polity Press, 1992.

Elster, Jon. Nuts and Bolt for the Social Sciences. Cambridge: Cambridge University Press, 1989.

Explaining social behaviour. More nuts and bolts for the Social Sciences. Cambridge: Cambridge University Press, 2007.

Frangie, Samer. "Bourdieu's Reflexive Politics: Socio-Analysis, Biography and SelfCreation", European Journal of Social Theory, 12/2 (2009): 213-229.

Fuchs, Christian. "Some Implications of Pierre Bourdieu's Works for a Theory of Social Self Organization", European Journal of Social Theory, 6/4 (2003): 387-408.

Gartman, David. "The strength of weak programs in cultural sociology: A critique of Alexander's critique of Bourdieu", Theory and Society, 36/5 (2007): 381-413.

Halewood, Michael. A.N. Whiteahead and Social Theory. Tracing a Culture of Thought. London and New York: Anthem Press, 2011.

Homans, George. "What do we mean by Social “Structure”?". In Peter Blau (Ed.), Approaches to the study of Social Structure. New York: The Free Press, (1975): 53-65.

Jenkings, Richard. Pierre Bourdieu. London and New York: Routledge, 2006.

."Beyond social structure". In Peter Martin \& Alex Dennis (Eds.), Human agents and social structures. Manchester: Manchester University Press, (2010): 133-151.

King, Anthony. The structure of Social Theory. London: Routledge, 2004.

Layder, Dereck. Understanding Social Theory. London: Sage, 1994.

López, José \& Scott, John. Social Structure. Buckingham: Open University Press, 2008.

Porpora, Douglas. "Social Structure: The future of a Concept". In Sing Chew \& David Knottneurs (Ed.), Structure, culture and history: recent issues in social theory. Boston: Rowman \& Littlefield, (2002): 43-62.

Rancière, Jacques. Disagreement. Politics and Philosophy. Minneapolis: University of Minnesota Press, 1999. 